\title{
"TPACK Stories": Schools and School Districts Repurposing a Theoretical Construct for Technology-Related Professional Development
}

Judi Harris

College of William and Mary

Mark J. Hofer

College of William and Mary

Follow this and additional works at: https://scholarworks.wm.edu/educationpubs

Part of the Teacher Education and Professional Development Commons

\section{Recommended Citation}

Harris, J., \& Hofer, M. (2017). "TPACK stories": Schools and school districts repurposing a theoretical construct for technology-related professional development. Journal of Research on Technology and Education, 49(1-2).

This Article is brought to you for free and open access by the School of Education at W\&M ScholarWorks. It has been accepted for inclusion in School of Education Articles by an authorized administrator of W\&M ScholarWorks. For more information, please contact scholarworks@wm.edu. 


\title{
“TPACK Stories:" Schools and School Districts Repurposing a Theoretical Construct for Technology-Related Professional Development
}

\author{
Judith B. Harris \& Mark J. Hofer \\ School of Education \\ College of William \& Mary \\ Williamsburg, Virginia 23185 \\ judi.harris@wm.edu_mark.hofer@wm.edu
}

This is an Accepted Manuscript of an article published by Taylor \& Francis in the Journal of Research on Technology in Education on March 27, 2017, available online here:

http://www.tandfonline.com/doi/full/10.1080/15391523.2017.1295408.

It is shared here according to the publisher's instructions to authors.

\section{Citation:}

Harris, J. B., \& Hofer, M. J. (2017). “TPACK stories:” Schools and school districts repurposing a theoretical construct for technology-related professional development. Journal of Research on Technology in Education. Advance online publication. doi: 10.1080/15391523.2017.1295408

\begin{abstract}
TPACK (Koehler \& Mishra, 2008), a theoretical construct that describes the knowledge that teachers use to teach with digital tools and resources, has flourished in university-based teacher education and research. Increasingly, K-12 schools and districts have also appropriated TPACK in their professional development efforts. This study of seven schools and districts explored how the TPACK construct was understood and used in these K-12 organizations. Study results revealed the importance of context and professional culture in appropriating the construct; the use of TPACK as a way to connect disparate professional development initiatives; TPACK conceptualized as applied knowledge; and how educational leaders' beliefs about professional development shape how TPACK is understood and enacted.
\end{abstract}




\section{Introduction}

How have K-12 schools and school districts used the theoretical construct called TPACK (technology, pedagogy, and content knowledge; Koehler \& Mishra, 2008) to conceptualize and structure professional development with and for their teachers? The purpose of this inquiry was to help selected K-12 professional development providers to share details of their TPACK-based professional development—-their "TPACK stories"— with each other and with the educational technology research community. In doing so, we analyze how the TPACK construct, which originated in university-based research and teaching, has been interpreted and enacted in seven K-12 school and district contexts.

\section{Theoretical Framework and Literature Review}

Seven components of the TPACK construct - TK, PK, CK, TPK, TCK, PCK and TPACK have been scrutinized with increasing fervor by educational technology researchers, especially in recent years (e.g., Angeli, Valanides, \& Christodoulou, 2016; Brantley-Dias \& Ertmer, 2013; Voogt, Fisser, Pareja Roblin, Tondeur, \& van Braak, 2013). The eighth component - the many and varied contexts within which all of these aspects of teachers' knowledge develop and are situated - has received comparatively little attention from TPACK researchers (Rosenberg \& Koehler, 2015), even though it was included in Angeli \& Valanides' (2005) conceptualization of technological pedagogical content knowledge (TPCK) and was added to Koehler \& Mishra's TPACK in 2008.

Contextual knowledge encompasses the many physical, interpersonal, technological, social, political, economic, cultural, geographic, and other characteristics of students' and teachers' current and past experiences and attributes, both in school and outside of it. This knowledge informs and mediates instructional knowledge and practice, including TPACK 
and curriculum-based technology integration. Cox (2008) therefore reminds us that "TPACK is unique, temporary, situated, idiosyncratic, adaptive, and specific, and will be different for each teacher in each situation" (p. 47).

Porras-Hernandez \& Salinas-Amescua's (2013) re-examination and redefinition of contexts within the TPACK construct argues that they can be understood within two dimensions: scope and actor. Social, political, economic and technological conditions and objects shape teachers' knowledge at macro (national/global), meso (local/institutional), and micro (classroom) levels of scope. Both student and teacher actors, all with "unique internal and external contexts" are complex and important "objects of knowledge" to be considered (p. 231). The specific nature of enacted TPACK is therefore dependent upon contextual characteristics, as Porras-Hernandez \& Salinas-Amescua illustrate with examples from their research in Mexico.

Given this highly situated nature of teachers' TPACK—-much of which we do not yet understand fully (Rosenberg \& Koehler, 2015; Porras-Hernandez \& Salinas-Amescua, 2013) - it is probable that the construct is conceptualized and operationalized differently in college/university and preK-12 school professional development contexts. Yet teachers' TPACK has been explored to date almost exclusively by university-based researchers, often connected to professional development efforts that are either sponsored by or conducted with higher education partners (Harris \& Hofer, 2014). This may be because the construct originated in higher education (Angeli \& Valanides, 2005; Koehler \& Mishra, 2005; Niess, 2005), was intended for use by teacher educators (Brantley-Dias \& Ertmer, 2013), and is popular among university-based educational technology researchers (Koehler, Mishra, Kereluik, Shin \& Graham, 2014; Voogt, et al., 2013). Yet TPACK has found its way into 
schools and school districts' professional development plans, procedures, and policies (Harris \& Hofer, 2014). How is the construct understood and used outside of higher education? We explored answers to this question with a multiple case study conducted across seven $\mathrm{K}-12$ contexts.

\section{Research Questions}

What is the nature and function of TPACK within and across differing school and school district contexts? How do these notions shape, guide and/or characterize the development of teachers' technology integration knowledge? This study examined the similarities and differences among a range of appropriations of the construct within seven K-12 schools or school districts.

\section{Methods}

\section{Participants}

To begin our study, we identified schools and districts that were using TPACK to frame, guide, and/or structure professional development by doing extensive Web searches. Approximately 70 schools and districts in North America, Australia, and the United Kingdom were located in mid-2013 that included TPCK or TPACK by name in materials posted online, with most located in the U.S., where the majority of TPACK work was occurring at the time (Chai, Koh \& Tsai, 2013). Of these, approximately 30 in North America addressed TPACK in comparative depth, illustrating the school or district's active use of the construct.

We invited representatives from 27 of these schools and districts-those that discussed TPACK as part of professional development most actively and recently-to attend a two-day TPACK-focused symposium at a southeastern U.S. university. Twelve 
school- or district-based professional development providers who work in six different U.S. states and one Canadian province requested participation in the symposium. They were asked to provide live, story-based presentations during the symposium about how TPACK is used to shape and/or frame aspects of the professional development offered in their educational organizations. We used an internal university faculty award to fund all symposium expenses, including food and hotel accommodations, save the participants' travel to and from the event, and offered a stipend of $\$ 200$ US per participant to help to defray some of the travel costs. Three participants' school districts did not permit them to accept the stipend.

\section{TPACK Symposium}

The symposium was designed to initiate information-sharing and in-depth discussion about the TPACK-based professional development that had emerged in each participating school or district. Representatives were provided with guidelines regarding the intended content of the presentations, asking them to use a style and voice similar to a TEDTalk (http://www.ted.com/talks). Participants' symposium presentations were videorecorded with their permission and shared via a website devoted to these "TPACK stories" (http://www.tpackstories.org/). In-depth discussion among the symposium's participants followed each presentation. Also, in the afternoons of each of the two days of the symposium, participants reflected in small and large groups about ideas encountered during the day's presentations and discussions that they planned to take back to their schools/districts. At the beginning of the second day of the symposium, the researchers presented emerging themes derived from the previous day's presentations and discussions, inviting participants' critiques and reflections. 


\section{Data}

The videorecorded presentations and audiorecordings of the accompanying indepth discussions among symposium participants comprised two of five types of data examined for this study. Participants' online application materials, which described the TPACK-based professional learning happening in their school or district, were the third type of data examined.

Each participating school or district also granted a follow-up interview, occurring approximately four months after the symposium ended. These semi-structured, memberchecked, audiorecorded telephone or Skype interviews - the fourth type of data generated for the study — were designed so that the researchers could co-construct with study participants deeper and more nuanced understandings of how TPACK is conceptualized, and how and why it is enacted in each of the schools or districts represented at the symposium.

Seven schools or school districts sent representatives to the symposium, with five districts sending two participants each—an administrator and an educational technology professional development provider-and two independent schools sending one representative each. Five of the follow-up interviews were conducted with one symposium participant (from three of the school districts and the two independent schools), and two were conducted with both symposium participants from the same school district concurrently. Interviews lasted between one hour and 3.5 hours each, with most having durations between 75 and 90 minutes, according to participants' wishes and availability.

The following interview questions were prepared prior to conducting the interviews, and were asked of all interviewees: 
1. How and when did you first find out about TPACK?

2. When did your school/district first start using TPACK? Why did it start to be used?

3. What does TPACK mean to you?
a. TPK?
b. TCK?
c. Contexts?

4. How is the development of teachers' TPACK (technology, pedagogy, and content knowledge) reflected and accomplished within the professional learning effort?

5. Why was TPACK used to frame this particular professional development effort?

Given the semistructured nature of the interviews, follow-up questions were asked that helped to expand and deepen the content of the responses to these six structured questions. All participants were also asked to add information that they saw as relevant to their school or district's use of the TPACK construct, even if it was not requested specifically by the interviewer.

Documents available on the schools' /school districts' Web sites (e.g., instructional technology vision statements that included explanation and application of TPACK), plus those shared by participants during the symposium that demonstrated and/or addressed the ways in which TPACK was used as a way to frame professional learning locally (e.g., classroom observation forms that were structured according to TPACK's components), comprised the fifth and final type of data analyzed in this study. 


\section{Data Analysis}

Symposium applications, presentations, and document data were analyzed holistically, thematically, and independently by the two researchers at first, with each separately noting emerging patterns and themes related to the study's two related foci: how TPACK is understood and enacted in the schools and districts whose representatives participated in the symposium. The researchers first read and reread the written data and viewed the videorecordings of the presentations multiple times, separately, writing memos that named and described the themes that emerged from this phenomenological examination of data (Vagle, 2014). After completing these individual holistic analyses of these first three types of data, the researchers conferred to combine, compare, critique and refine their data analysis notes, both during and after the symposium. Twenty-one initial themes emerged from processing the individually generated data memos in this way.

Audiorecorded group discussion data were analyzed by the researchers collaboratively during the symposium, keyed according to the study's two foci, immediately following each day's presentations and discussions. Interview data were later transcribed verbatim by a transcription service. All interview transcripts and audio files were then analyzed thematically, using a memoing procedure similar to the one used for the first three data types, by each of the researchers independently to reveal within-case and across-case themes. The researchers met again to scrutinize their interview data analysis notes, then considered, discussed, and agreed upon the themes and thematic interrelationships emerging across the five data types from the seven schools/districts that together comprise the study's results.

\section{Results}


Analysis of the five types of data generated by and with representatives from the seven schools or school districts participating in the TPACK Stories Symposium revealed a fascinating range of ways in which the construct is grasped and put into practice in each professional learning context. To illustrate this range and as a way to introduce the study's participants, we will first present profiles of each of the seven schools'/districts' use and understanding of TPACK. Then we will share five over-arching ideas about TPACK's functions, implementation, and nature that emerged from data analysis across the seven participating educational organizations.

In the seven participating schools/districts, TPACK served as a connector, a grassroots initiative, a check-and-balance, an instructional planning tool, a technological focus, a compass, and a collaborative process. Each and all of these roles for the construct are described in the seven "TPACK Profiles" that appear below.

\section{School/District Profiles}

TPACK as connector. Oak County Schools is a large and diverse public school district in the southern United States with approximately 60,000 students. Oak County provides professional development for teachers primarily through a network of more than 100 coaches who are assigned to multiple schools, and whose work is focused upon curriculum and curriculum-related pedagogy. They first encountered TPACK as representatives were writing a Federal grant proposal. Danielle, a district administrator whose work includes coordinating multiple aspects of professional development for Oak County, explained that when she and her colleagues "came across TPACK," it "seemed to kind of marry a lot of the initiatives that we were doing that had been going on" in the district and at the state level. 
During the academic year preceding the symposium, the district added eleven "TPACK Coaches" to an existing network of instructional coaches, each of whom works with a particular school that has committed to creating personalized learning in 1:1 computing environments for its students. In working with just one school each, these Oak County TPACK coaches are responsible for professional development for teachers in all curriculum areas, and specifically in technology integration as it can assist teachers in supporting students' personalized learning. Some of those teachers-who had either requested or have been recommended for more intensive individualized professional developmentwork with TPACK Coaches more closely for a period of six to nine weeks each. Although professional development can be organized either individually or in groups in Oak County, most teachers work with the coaches either alone or with their grade-level or content-area colleagues.

The TPACK Coaches were selected based upon their expertise with both technology integration and pedagogical content knowledge. They meet once weekly with other TPACK Coaches to build their own professional learning and collaboration, and often participate in the networking and professional development offered to the other curriculum-focused coaches in the district.

Danielle said that TPACK is used primarily as "a way to think" in her district; "it provides a great process for thinking through those main components [curriculum, pedagogy, and technology] that can help transform our learning." It has stopped what Danielle termed "backwards thinking" in the district about technology integration, such as "oh, this really cool technology...oh, where can I fit that into my curriculum?" Instead, it has helped Oak County to integrate technology use into somewhat disparate initiatives, 
connecting them together. According to Danielle, "TPACK was just the perfect construct to think about how we take all the components...and connect them into one."

A similar connecting function served by the construct was noted in the next district to be profiled, although the ways in which TPACK-based work originates and TPACK is expressed and are quite different.

TPACK as grass-roots initiative. Like Oak County Schools, Briarwood County Schools is a large school district located in the southern United States. Comprising more than 30 schools and 20,000 students, Briarwood is located mid-way between two urban centers and serves a diverse and changing student demographic. Encompassing both urban and rural populations, Briarwood experienced rapid growth during the previous several years in both student population and the proportion of students from lower socioeconomic strata. Karen, a district administrator who coordinates both professional learning and technology initiatives in the district, oversees a team of more than 20 technology integration support staff that provide both traditionally structured and job-embedded professional development experiences for teachers.

In contrast with Oak County, where discovery and use of TPACK district-wide is comparatively recent, Karen first encountered the TPACK construct in 2006 when a colleague attended a presentation by one of the construct's originators. Through subsequent study and conversation with her technology integration support staff, the group began to embed TPACK systematically into the design of professional learning experiences for teachers throughout the school system. With her responsibilities including both facilitation and supervision of instruction and technology use and professional learning, Karen saw an opportunity to utilize the construct to "align the division's 
investment in digital tools to support specific content and curricular goals" that had been targeted for development by district administrators.

As in Oak County, Briarwood's leaders integrated TPACK intentionally within the existing coaching and professional learning community (PLC) structure for professional development in the district. In contrast with the more systemized approach in Oak County, though, Briarwood has taken a more "grass-roots" approach that is led by teachers. In essence, according to Karen, they have "flipped the emphasis on Central Office pushing down initiatives to a professional learning community approach where teacher leaders are pushing up." Technology integration support staff members have worked individually with teachers in planning for and/or modeling educational technology use that reflects the integration of technological, pedagogical, and curriculum knowledge represented within the "sweet spot" in the middle of the TPACK diagram. More recently, Karen has orchestrated the formation of teams of teacher-leaders with content area, technology, and pedagogical expertise who collaborate to support groups of other teachers working within the district's PLCs.

Donna, a member of the technology integration support team, described the teachers working within these PLCs as "naturally utilizing the construct [in their planning], whether they know that it is called TPACK or not." This suggests that in Briarwoods' "grassroots" approach to TPACK-related professional development, understanding the theoretical aspects of the construct is less important than supporting teachers in applying TPACKrelated principles in their classroom practice. This is also the case in Oak County, where TPACK-related professional development is more formally and centrally structured. By 
contrast, in the next district to be profiled, TPACK-related professional development is enacted with conscious and frequent reference to the construct.

TPACK as check-and-balance. Mountain Park School District is located just outside a major city in the western region of the United States. A suburban district, Mountain Park serves approximately 15,000 students in 20 schools. Like Briarwood, Mountain Park has a long history with the TPACK construct. Teachers and administrators first encountered the construct through a presentation at a state-wide educational technology conference in 2008. Since then, district technology and learning specialists have collaborated in a very systematic, widespread effort to use the TPACK construct to structure professional development experiences for teachers that emphasize literacies and skills for the $21^{\text {st }}$ century.

Learning about the TPACK construct catalyzed bringing district technology and learning specialists together to develop professional learning experiences for teachers collaboratively. Mollie, a district learning specialist, noted that the TPACK construct serves "as a visual vehicle and common language" to enable the two departments to work effectively together. This collaboration is evident in the design and implementation of a professional development initiative focused on technology-enhanced writing. As a part of this and other professional learning experiences in the district, facilitators guide teachers through a series of "TPACK Scenarios" in which they collaboratively deconstruct lessons to determine the relative "fit" of the content, pedagogy and technology in a lesson.

In addition to these traditionally structured professional development experiences, Mountain Park emphasizes the importance of modeling and co-teaching for assisting teachers to integrate technology effectively in their teaching. Sharon, a district technology 
specialist, suggests that through this modeling, "while the kids are learning how to do it, the teacher is watching and learning at the same time while we're in the classroom with their kids." Modeling is particularly effective in helping teachers to explore ways to manage technology use in the classroom. Mollie noted, "Literally I would say $95 \%$ of what I do is modeling in the classroom; walking teachers through how this works and [what it] looks like."

In contrast with Briarwood's efforts in using TPACK as a theoretical construct to provide opportunities for teachers to develop their technology integration knowledge, Mountain Park leverages the construct more as a means to encourage "balanced," studentcentered technology integration efforts. Through TPACK Scenario discussions and instructional modeling, they use the construct primarily as a technology integration tool "as a check and balance" - to help teachers aim for "the sweet spot in the middle." To help challenge teachers to strive towards more robust, student-centered uses of technology in their teaching, they have paired the TPACK construct with the Substitution Augmentation Modification Redefinition (SAMR) model (Puentedura, 2006). In pairing these two models, they attempt to encourage teachers to move to higher levels and qualities of technology use. Sharon summarizes, "So what we say with teachers is not 'are you using tech,' it's 'how are you using tech?'” For Mountain Park, using the TPACK construct in combination with the SAMR model has helped to create a roadmap for effective technology integration for teachers in the district. This pairing of TPACK with SAMR is reflected in the next district's profile as well.

TPACK as instructional planning tool. The Green County school district serves nearly 150,000 students in the southern United States. This large district is diverse in 
terms of racial and ethnic composition, geographic area, and socioeconomic status. Green County is a highly complex organization, comprising 11,000 teachers, 171 schools and seven different instructional calendars. Professional learning, particularly in the form of professional learning communities (PLC's), has been a major focus in the district.

Joann, the district technology specialist, first learned about the TPACK construct at the 2011 ISTE conference when she attended a session on the TPACK-based Learning Activity Types (LAT) approach to instructional planning (Harris \& Hofer, 2009). She commented, "it was one of those moments when the sky opens up and light shines and you realize, 'this is what I was looking for.'” Joann saw the LAT approach as a way to help teachers to operationalize TPACK in their classrooms. As in Briarwood, the theoretical aspects of the TPACK construct were less important to Joann than supporting teachers in applying TPACK-related principles in classroom teaching. For her, ...the construct did not make a whole lot of difference.... But what made sense to me was the Activity Types. [They] very simply became a bridge between the two mountains of "here's what I've learned, and here's how I apply it."

To make the LAT taxonomies maximally useful to teachers in Green County, Joann and her staff customized them to include state learning standards and digital tools and resources that were available in the district.

As illustrated in each of the first three profiles, Green County leaders were deliberate in integrating the TPACK construct as well as the LAT approach within the existing professional learning culture in the district - primarily through long-established PLC's. Rachel, a Green County curriculum leader, characterized this approach to supporting teacher learning for technology integration as a "move from unintentional to intentional." 
Technology integration facilitators in the district utilized the PLCs to disseminate the LAT approach. Joann explained,

At that time, my staff was already in professional learning communities in schools, or they were meeting with small groups in schools, and so as they were doing that they made sure they had the activity types there with them, and were able to leave a copy, share a copy digitally, and so then propagate.

This emphasis on using TPACK for instructional planning has been key to the success of the initiative in Green County. Joann commented, “That's when we started to see some work actually happening for us - when we hit [the teachers] at the planning level, not at the 'I have to go to a workshop' level."

As in Green County, the TPACK construct in Canton Public Schools serves as an organizing framework for teacher practice, rather than a focus for conceptual learning for teachers.

Tool-focused TPACK. Canton Public Schools is a relatively small district in the midwestern United States. Comprising nine schools, this suburban district just outside a large city serves just over 5000 students. After experiencing some frustration with toolfocused, workshop-based approaches to educational technology professional development, Eric, a technology facilitator in the district, learned about the TPACK construct in his graduate coursework. He described TPACK as "the thoughtful integration of technology," and was particularly interested in the synergistic nature of content, pedagogy and technology that is expressed in the construct. The notion that "adding technology changes something" - an idea emphasized by TPACK's authors —was powerful for Eric. In discussing technology and content, for example, he remarked, "I totally understood that 
leap that technology changes content and can have that impact." As part of a recent STEM initiative, Eric also noted how when the content changes, "you have to change your pedagogy, and we have to change our tools." This interaction among content, pedagogy and technology drives the professional development efforts in the district for technology integration.

Canton has shifted to what Eric describes as a TPACK-based "focus tools" approach to professional development for teachers. In this model, the district has selected a limited number of flexible tools that can be used in a variety of content areas, supporting teachers in developing their knowledge of the pedagogical affordances and constraints of each of these tools. In this three-phase approach, teachers first develop "foundational" knowledge about how to use the focus tools in a traditional workshop setting. Once teachers are comfortable using the tools, the focus then shifts to assisting them in considering the affordances and constraints of the tools when using them in the classroom. Eric recommended,

Don't talk about tools as pros and cons, but rather understanding affordances and constraints, and that's a way to really develop that TPACK, or at least maybe the TPK. What [do these tools] allow me to do? What do I need to take into consideration when planning lessons?

The third phase of the approach helps teachers to design lessons that utilize the focus tools. Eric recognized that a TPACK-based approach that begins by focusing on tools may seem counterintuitive. He argued, however,

It was really all about trying to build [the teachers'] capacity to use the tool and then to be able to make those independent choices. Just as we were [doing] with kids, it 
was ... scaffolding; we're building them towards that independence. Yeah, we did focus on using that tool to drive [the professional development], but we're building in... the rationale of when to use [them], so that hopefully ... they can now make those choices on their own.

This scaffolded approach to tool choice and use is similar to Mountain Park's use of TPACK scenarios, although with less focus placed on the TPACK construct itself. The next two profiles describe more teacher-driven, organic approaches to professional development.

TPACK as compass. Blue Lake High School serves roughly 1000 students in a western Canadian city with emphasis in the fine arts and an International Baccalaureate program. Blue Lake is characterized by a distributed leadership model, described by its library/media specialist, Karen, as a way "wherein staff members with particular strengths are encouraged to cascade expertise in their areas throughout the school." During the last several years, professional development in the school has shifted from a more traditional top-down model to a teacher-directed PLC approach. This shift in control over teachers' professional learning reflects the broader vision of "respectfully honoring" the insight and experience of the excellent faculty of the school.

Karen recognized a clear connection between the TPACK construct and her school's approach to professional learning when she learned about the construct from a colleague. Professional development for technology integration in the past had been focused primarily on the tools, rather than how to teach with them. In integrating the TPACK construct into their thinking, "we wanted to put students and curriculum first. TPACK just matches that perfectly. It puts technology where it should be." Like most of the other symposium participants, Karen doesn't teach teachers about the construct specifically. 
Instead, “TPACK does not so much 'frame' professional development at our school ... as provide a strong underpinning for educational technology PD that itself supports other professional inquiries."

Karen characterizes the TPACK construct as a kind of "compass." She views TPACK as collaboratively built knowledge by teachers who are already accustomed to working in teams. The construct guides their work as they design technology-enhanced instruction together:

Who brings the pedagogical expertise, and who brings the technology that can facilitate that in order to make it work better? ...It's leveraging each of the technology, the pedagogy, and the content. No single individual is pulling from all, ...but as a team, we [are].

At Blue Lake, teachers share their experience, curricula and learning activities that they have designed through a school Web portal or "landing page," which Karen describes as “a safe place where teachers can visit the 'classrooms' of those colleagues who are venturing into placing class processes or resources on a website." This collaborative approach to curriculum design is also reflected in this study's final TPACK profile; and yet, the way in which TPACK is held in these two different school contexts is quite distinct.

TPACK as collaborative process. The Orchard School is a non-sectarian K-8 private school located just outside a major metropolitan area of the eastern United States. The school serves just over 200 students with a rigorous academic curriculum and a robust arts program. When he arrived at the school three years ago, instructional technologist Michael brought with him lessons he had learned during his time working previously at two international schools. In these schools, he engaged regularly in collaborative 
instructional review and design with other teachers. Michael prefers collaborative, "organic" professional development opportunities to more traditionally structured workshops.

Michael first learned about the TPACK construct through a series of articles published in Learning \& Leading with Technology in 2009. His first exposure to the construct was similar to Joann's in that these articles focused on helping teachers to develop their TPACK through the use of the LAT approach. Michael recognized many similarities between this applied version of TPACK and the curriculum review and design process that he had developed and implemented with previous colleagues. He commented, "Wow, that's what we were doing in [Southeast Asia International School], when we didn't know what TPACK was." Like Joann, Michael was less concerned with the theoretical nature of the construct than "how do we make things practical?" For him, the process of bringing teachers, the library media specialist, and the instructional technologist together to design curriculum collaboratively was a way for the participants to develop their own TPACK. He referred to engaging in this process as "TPACKing."

Michael sees TPACK as distributed, rather than knowledge that is individually held by teachers. A self-described social constructivist, he, like Karen at Blue Lake, recognized that teachers and specialists could learn from each other as they each contribute individual knowledge and expertise to the discussion of curriculum. In this way, Michael views TPACK as distributed expertise that can be leveraged in collaborative development of curriculum. He describes the dynamic of "TPACKing" during a curriculum review as: "You're sitting around that big table. You can almost see these ideas from the different knowledge areas coming together in the middle of that table, just swirling around." He argues that the more 
teachers engage in this kind of process, the more they develop their own TPACK organically. He sees this process as regular, ongoing professional development. In fact, he said, “It isn't like we were running professional development programs outside of this. The meetings themselves...were such great learning opportunities for the different partners in the curriculum development process."

Having now been introduced to how TPACK is understood and enacted in each of the seven distinct educational contexts represented at the symposium, what is common to all?

\section{Findings Across Contexts}

Five broad commonalities about how the participating schools and school districts conceptualized and enacted TPACK in teachers' professional development (PD) emerged. These address the strong influence of local context and culture; the use of the construct to connect disparate PD initiatives; the importance of "meeting teachers where they are" for professional learning; the highly applied (as opposed to theoretical) nature of TPACK; and how beliefs about TPACK shape how it is enacted. These broader findings are described and illustrated below.

Context and culture. As we hope is evident in the seven school/district profiles presented above, the importance of context and professional culture in planning and implementing educational technology-related professional development cannot be overstated. The symposium participants appropriated TPACK in ways that were congruent with their schools' or school districts' unique cultures, initiatives, histories, and values.

For example, in Briarwood County, student demographics have shifted demonstrably during the past several years. Teachers in the district expressed some 
concerns with their ability to reach the increasing number of English language-learning students entering their classrooms. The technology director for the school district used Universal Design for Learning (UDL) and TPACK as a way to frame professional learning to help teachers to see their curriculums differently, helping them to identify technologicallyenriched strategies to support their students' differentiated learning needs. To plan and implement the professional development required with this new approach, the leaders employed the teacher leadership model already in place in the district. Rather than designing a "one-size-fits-all" approach, they identified teacher leaders with different expertise (e.g., content experts, special education teachers, instructional technology resource teachers) to develop curriculum and professional learning experiences for teachers collaboratively. Similarly, in Oak County, the technology and curriculum directors utilized a well-established instructional coaching model to support educational technology professional development. This approach was both familiar and effective for teachers in supporting the incorporation of technologies in ways that personalized student learning - a key initiative in the district.

In addition, interviews with symposium participants suggested that the ways in which TPACK was introduced and built upon in each school or district reflected the usual decision-making and implementation processes applied to professional developmentrelated change in each educational organization. Some, like Oak County, Green County, and Canton, disseminated TPACK-based learning opportunities in a more centralized and standardized way; while others, like Blue Lake and Orchard, introduced TPACK-like ideas more organically. Others, such as Briarwood County and Mountain Park, combined "topdown" and "grass-roots" methods when structuring and facilitating TPACK-based 
professional development for teachers. Existing contexts and cultures in the participating schools and districts also informed how they attempted to connect seemingly disparate professional development initiatives, which will be summarized in the next section.

Connecting disparate PD initiatives. All but one of the school/school district representatives participating in the study described how the TPACK construct is helping professional development providers - and in several cases, other school or district administrators, too-to connect what appear to be disparate change initiatives occurring simultaneously, such as personalized learning, 1:1 computing, Universal Design for Learning, instructional coaching, and professional learning communities. These participants referenced the comprehensive nature of the construct, which comprises pedagogy, curriculum/content, technology, and multilayered teaching/learning contexts, as the reason why TPACK works well as an organizational and conceptual umbrella for multiple and simultaneous change initiatives related to the development of teachers' knowledge and practice. Since educational change initiatives in schools and districts must incorporate teacher learning to be successful, and typically address some combination of pedagogy, curriculum, technology, and/or contextual factors, it should be no surprise that the TPACK construct was embraced by symposium participants as a way to "marry" multiple school or district change efforts.

An interesting example of this connective function of the construct was illustrated in different ways in both the Mountain Park and Green County school districts, and also (more informally) in the Orchard School. Each of these organizations chose independently to combine intentional use of TPACK with Puentedura's (2006) Substitution Augmentation Modification Redefinition (SAMR) model, explaining that the somewhat technological focus 
of SAMR's message about the essential functions and sophistication of educational technology use partners well with TPACK's explicit attention to pedagogy, curriculum, and teaching/learning contexts. Indeed, Puentedura's work (2008) that recommends combining TPACK and SAMR communicates a similar perception.

In Green County, when Joann first attempted to integrate the TPACK construct with existing educational technology professional development initiatives, she acknowledged that the SAMR model already structured many PD efforts in the district. As she began to consider how TPACK and SAMR might be combined, she realized how they might work to support one another. She described TPACK as a "three legged stool." She explained:

So, our construct basically looks like a three-legged stool, where technology, content, and pedagogy are the legs. So, they are the foundation with which all digital literacy should happen. So, all three pieces should be there, and I tell people all the time if one isn't complete, and one is not rock solid, you know what happens to the stools.

She then thought about how the different levels of technology use described in the SAMR model might be incorporated as rungs connecting the legs of the stool. By combining these two models in this way, she has been helping teachers to develop "balanced" instruction that also encourages them to incorporate more robust, student-centered uses of technology in their teaching.

Another example of connecting disparate PD initiatives in a district was reflected in Mountain Park's story. In this district's state, $21^{\text {st }}$ century skills had been incorporated into all curriculum standards. Consequently, the integration of technology had been incorporated into the teacher evaluation system. To align the system with TPACK, Mollie 
met with district professional development and administrative representatives to ensure that items on the district's teacher evaluation form reflect each of the eight aspects of the TPACK construct.

Meeting teachers where they are. Given TPACK's comprehensiveness concerning the nature of teachers' work and expertise, and its resulting contextual flexibility, many of the study participants described their TPACK-related work as being particularly sensitive to teachers' differing professional strengths and learning needs. They reported that the construct helped them conceptually and organizationally to both honor teachers' professional experience-incorporating their curricular and pedagogical expertise directly and actively - while concomitantly helping teachers to further develop that knowledge and practice with well-informed, judiciously chosen digital tools and resources applied in effective ways. Karen summarized this by describing her role in assisting her teachers' technology integration efforts as being "able to support teachers in excellence." During her post-symposium interview, she reflected, rhetorically, "How could I not work respectfully [with the teachers], honoring what they bring to the table?"

For our study's participants, an important part of "meeting teachers where they are" in professional development related to effective educational technology use involved focusing educational technology PD more upon curriculum, context, and (especially) pedagogy than upon technology. Most symposium participants reported that a key reason that the TPACK framework first appealed to them was the failure of previous toolfocused/technocentric approaches to professional development for teachers in their schools or districts. 
Joann, for example, reported on a prior educational technology effort that was initiated and developed by central office administrators. This "top-down" approach focused on use of a large influx of technology tools and resources, and was not well received by teachers. Joann noted that starting with and focusing upon the nature and operation of the tools themselves was ineffective with teachers in her district, which made a TPACK-based approach, once discovered, quite appealing. In another district, Danielle described the writing of a technology-focused grant proposal that was not funded. With the opportunity to reconsider the proposed initiative, the proposal's developers shifted their focus to using technology as a TPACK-based means to personalize learning for students while increasing the students' engagement in learning. Framing the initiative in this student-focused way proved to be considerably more successful for teachers in Oak County Schools.

TPACK as applied, not theoretical, knowledge. Our participants argued emphatically that TPACK-focused PD should be practice-based and personalized for teachers. There was clear consensus that while knowledge of the construct can be helpful to classroom practitioners, a focus upon applied knowledge in practice, rather than theory, is critical to success. This focus took different forms in the schools and school districts represented. The use of the construct to guide professional learning was systematic and strategic in some districts (such as Canton and Green), and more organic, emergent, and faculty-driven in others (such as Briarwood and Blue Lake).

In Canton Public Schools, for example, Eric explained that there was significant emphasis placed upon helping teachers to understand how to teach well with particular technologies - an approach that emphasized technological pedagogical knowledge (TPK). To make this process more efficient for both support staff and teachers, developers 
identified a number of "focus tools" - a set of widely available tools that could be used in various ways in different content areas. They then structured the professional development to help their teachers build their TPK with these focus tools, linking their use to curriculum-based "power standards" previously identified in their district.

In other schools and districts represented at the symposium, the process was more organic and faculty-driven. In Briarwood County, for example, teachers choose to participate in one of a number of different professional learning communities (PLCs). Many of these PLC's focus, in part, on some aspect of technology integration. Through an iterative process of action research, experimentation, and sharing teachers' experiences through a Web-based portal, the district facilitated a form of job-embedded, personalized learning that is helping teachers to develop their TPACK.

Some symposium participants, like Joann in Green County, suggested that knowledge of the TPACK construct is not necessary for teachers. Instead, attending to and (especially) balancing focus upon strengthening teachers' content, pedagogy, and technology knowledge-as represented by the TPACK construct—was seen by symposium participants as essential to success. In this way, the construct can serve as a compass, guide, or self-check for both classroom teachers and professional development providers.

Beliefs about PD shape how TPACK is understood and enacted. Paralleling some aspects of Ertmer's research (2005) about how teachers' beliefs predict and shape the quality and sophistication of their instructional uses of educational technologies, our data analysis suggests that participating school- and district-based professional development providers' beliefs about PD shaped how TPACK is both understood and enacted within each of their organizational contexts. Examples of these TPACK-related epistemologies follow. 
Technology ("T") changes everything. To Eric in Canton Public Schools, for example, who has read and blogged extensively about the TPACK construct, one of the most compelling aspects of the construct is found in the interrelationships and interdependencies of technology, pedagogy, and content. Echoing some of the earliest TPACK publications by Mishra \& Koehler (2005; 2006), Eric is convinced that technology use changes both pedagogy and curriculum content in pervasive ways. Consistent with these beliefs, Eric's “focus tools" approach to TPACK-based professional development for teachers (described above) centers upon helping them to understand and be able to apply key technological tools' particular and distinctive affordances and constraints.

“Doing" TPACK is "more important than knowing about it." Joann in Green County barely remembered her earliest encounters with the TPACK construct through graduate work at a local university. When she discovered the TPACK-based Learning Activity Types (Harris, Hofer, Blanchard, Grandgenett, Schmidt, van Olphen, \& Young, 2010), however, as described earlier in this article, the construct came alive for her. For Joann, "Lots of [educational] theories sound great, but [when] you show me how to apply [the theory], that's really what kind of got it for me." Hence, in Joann's district, TPACK PD work focuses upon instructional planning (for which the LATs were developed) for curriculum-based learning and teaching.

TPACK helps to personalize learning-for everyone. The great majority of Oak County's professional development for teachers is situated within and provided by a network of instructional coaches. The district's strong belief in the efficacy of personalized learning is reflected in its ambitious goal of providing an individualized learning plan for each and all of the district's more than 65,000 students. A similar belief in the importance 
of personalizing learning for teachers is expressed in the district's support of a network of more than 140 curriculum- and pedagogy-focused instructional coaches, including 11 "TPACK Coaches" that work in some of the district's most challenged schools.

TPACK is built by teachers collaborating. On each day at the Blue Lake School, teachers engage in collaborative planning for instruction and decision-making about school operation. Karen described the key role that a collaboratively built virtual space plays at her school in highlighting teachers' successful work, sharing resources, and discussing efforts to integrate technology. The teachers' collaborative work is highlighted regularly on this "landing page" of the school's Web site, and it is in this ongoing endeavor that Karen sees TPACK being built at her school. In addition to providing access to many helpful stories and resources for classroom teachers, this public display of teachers' work demonstrates how much it is valued by the school community.

The nature of the work at the Blue Lake School was similar to reports of EcoScienceWorks, a much larger-scale project in Maine that involved collaborations among middle school science teachers, environmental educators, simulation software developers, and facilitators for a statewide ongoing one-to-one laptop program, all of whom worked together to produce and test a TPACK-keyed, teacher-written curriculum. Project facilitators reported that the "collaboration was designed to provide teacher professional development as an outgrowth of teachers becoming involved in the project's tasks specifically to write a curriculum that integrated...computer simulations into their teaching" (Allan, Erickson, Brookhouse, \& Johnson, 2010, p. 37). Several university-based projects have used similar collaborative, constructionist models for teachers' TPACK development (e.g., Kafyulilo, Fisser, \& Voogt, 2014; Polly, 2011). 
TPACK is distributed knowledge. Michael helped the teachers at his school to use team-based curriculum planning as a strategy to develop their TPACK. The curriculum review team at Michael's school comprised classroom teachers, the school library media specialist, the instructional technologist, and an administrator. During the curriculum review process, each group member brought his or her expertise to the team in this collaborative planning process - to such an extent, Michael reported, that the knowledge built together cannot be held fully by any single member of this professional community. Therefore, to Michael, TPACK cannot be held individually, even (and especially) after being built collaboratively. It is truly distributed knowledge, existing in the spaces and efforts for collaboration among teachers working together daily on curriculum and instruction. Several TPACK researchers (e.g., Di Blas, Paolini, Sawaya, \& Mishra, 2016; Nore, Engelienm \& Johannesen, 2010) have expressed similar perspectives.

Considering the seven individual school/school district "TPACK profiles" and the five across-participant findings described here, it is probable that TPACK is both understood and enacted in K-12 schools and districts quite differently from how it is conceptualized and operationalized at present by university researchers and developers (Harris \& Hofer, 2014). This realization suggests a number of intriguing questions and possible directions for future research.

\section{Discussion}

Our participants' nuanced understandings and applications of TPACK, presented here, diverge from scholars' interpretations of the construct in many ways. Schools' and districts' emphasis on teacher practice and action suggests a potential shift away from using TPACK primarily as a way to understand teachers' knowledge for technology 
integration. Instead, this study's participants more often articulated TPACK as a way to help balance emphasis on content, pedagogy and technology in the design and implementation of professional development experiences for teachers. This approach focuses more on ensuring that none of the three primary elements within the construct are either omitted or over-emphasized, than on the specific nature or development of teachers' technology integration knowledge, as much current academic research in the area addresses (Voogt, et al., 2013).

This pragmatic use of the construct was echoed in the few publications that report intentional TPACK use in schools and districts other than the ones explored in this studyfor example, in the San Diego Unified School District (LaFee, 2010), where "TPACK emphasizes how content, pedagogy, and technology can be overlapped to create more effective educational environments" (p. 49), and multiple school districts in Maine, where "each of the elements of TPACK (technology, pedagogy, and content knowledge) worked together to produce [a teacher-written] ecology simulation-centered curriculum" (Allan, et al., 2011, p. 36). In fact, when leaders in one district in New York attempted to use TPACK more theoretically (and overtly) within professional development for a group of mathematics and science high school teachers, the participants critiqued the conceptual parts of the PD, while simultaneously demonstrating clear understanding and productive application of the construct and its subcomponents in their classrooms (McGrath, Karabas, \& Willis, 2011).

Might the differences between school and district-based results and other examinations of teachers' TPACK development be artifacts of how the construct has been conceptualized and investigated by colleges and universities? Is the nature of the TPACK 
that is being built in schools and districts different from the nature of the TPACK acquired through university-based courses, structured modeling and coaching, and other, betterdocumented TPACK development methods that involve higher education contexts and partners?

How we answer these questions, as researchers and as teacher educators working in multiple educational contexts, will determine-perhaps to a larger extent than previously acknowledged-how the understanding, development, and enacting of TPACK will continue to evolve as it is built and used in educational organizations of all types.

\section{References}

Allan, W. C., Erickson, J. L., Brookhouse, P., \& Johnson, J. L. (2010). EcoScience works: Teacher professional development through a collaborative curriculum project - An example of TPACK in Maine. TechTrends, 54(6), 36-43.

Angeli, C., \& Valanides, N. (2005). Preservice elementary teachers as information and communication technology designers: An instructional systems design model based on an expended view of pedagogical content knowledge. Journal of Computer Assisted Learning, 21(4), 292-302.

Angeli, C., Valanides, N., \& Christodoulou, A. (2016). Theoretical considerations of technological pedagogical content knowledge. In M. C. Herring, M. J. Koehler, \& P. Mishra (Eds.). Handbook of technological pedagogical content knowledge (TPACK) for educators (2nd ed., pp. 11-32). New York: Routledge. 
Brantley-Dias, L., \& Ertmer, P. A. (2013). Goldilocks and TPACK: Is the construct "just right?" Journal of Research on Technology and Education, 46(2), 103-128. doi:10.1080/15391523.2013.10782615

Chai, C.-S., Koh, J. H.-L., \& Tsai, C.-C. (2013). A review of technological pedagogical content knowledge. Educational Technology \& Society, 16(2), 31-51.

Cox, S. (2008). A conceptual analysis of technological pedagogical content knowledge (Doctoral dissertation). Retrieved from ProQuest Dissertation and Theses. (AAT 3318618)

Di Blas, N., Paolini, P., Sawaya, S. \& Mishra, P. (2014). Distributed TPACK: Going beyond knowledge in the head. In M. Searson \& M. Ochoa (Eds.), Proceedings of Society for Information Technology \& Teacher Education International Conference 2014 (pp. 2464-2472). Chesapeake, VA: Association for the Advancement of Computing in Education (AACE). Retrieved from https://www.learntechlib.org/p/131154

Ertmer, P. A. (2005). Teacher pedagogical beliefs: The final frontier in our quest for technology integration? Educational Technology Research and Development, 53(4), 25-39.

Harris, J., \& Hofer, M. (2009). Instructional planning activity types as vehicles for curriculum-based TPACK development. In Association for the Advancement of Computing in Education (Eds.). Research highlights in technology and teacher education 2009 (pp. 99-108). Chesapeake, VA: AACE.

Harris, J., \& Hofer, M. (2014). The construct is in the eye of the beholder: School districts' appropriations and reconceptualizations of TPACK. In L. Liu \& D. Gibson (Eds.), 
Research highlights in technology and teacher education 2014 (pp. 11-18). Waynesville, NC: AACE.

Harris, J. B., Hofer, M. J., Blanchard, M. R., Grandgenett, N. F., Schmidt, D. A., van Olphen, M., \& Young, C. A. (2010). "Grounded" technology integration: Instructional planning using curriculum-based activity type taxonomies. Journal of Technology and Teacher Education, 18(4), 573-605.

Kafyulilo, A., Fisser, P., \& Voogt, J. (2014). Teacher design in teams as a professional development arrangement for developing technology integration knowledge and skills of science teachers in Tanzania. Education and Information Technologies, 19(2), 1-18. doi: 10.1007/s10639-014-9321-0

Koehler, M., \& Mishra, P. (2008). Introducing TPCK. In AACTE Committee on Innovation and Technology (Ed.), Handbook of technological pedagogical content knowledge (TPCK) for educators (pp. 3-31). New York: Routledge.

Koehler, M. J., \& Mishra, P. (2005). What happens when teachers design educational technology? The development of technological pedagogical content knowledge. Journal of Educational Computing Research, 32(2), 131-152.

Koehler, M. J., Mishra, P., Kereluik, K., Shin, T. S., \& Graham, C. R. (2014). The technological pedagogical content knowledge framework. In J. M. Spector, M. D. Merrill, J. Elen, \& M. J. Bishop (Eds.), Handbook of research on educational communications in technology (pp. 101-111). New York: Springer.

LaFee, S. (2010). Taking the i21 initiative: San Diego USD looks to transform teaching and learning through technology. California Schools Magazine, 68(2), 47-51. 
McGrath, J., Karabas, G., \& Willis, J. (2011). From TPACK concept to TPACK practice: An analysis of the suitability and usefulness of the concept as a guide in the real world of teacher development. International Journal of Technology in Teaching and Learning, 7(1), 1-23.

Mishra, P., \& Koehler, M. J. (2006). Technological pedagogical content knowledge: A framework for teacher knowledge. Teachers College Record, 108(6), 1017-1054.

Niess, M. L. (2005). Preparing teachers to teach science and mathematics with technology: Developing a technology pedagogical content knowledge. Teaching and Teacher Education, 21(5), 509-523.

Nore, H., Engelien, K., \& Johannesen, M. (2010). TPACK as shared, distributed knowledge. In D. Gibson \& B. Dodge (Eds.), Proceedings of the Society for Information Technology \& Teacher Education International Conference (pp. 3920-3925). Chesapeake, VA: Association for the Advancement of Computing in Education (AACE). Retrieved from https://oda.hio.no/jspui/bitstream/10642/354/2/522024post.pdf

Polly, D. (2011). Teachers' learning while constructing technology-based instructional resources. British Journal of Educational Technology, 42(6), 950-961. doi:10.1111/j.1467-8535.2010.01161.x

Porras-Hernández, L. H., \& Salinas-Amescua, B. (2013). Strengthening TPACK: A broader notion of context and the use of teachers' narratives to reveal knowledge construction. Journal of Educational Computing Research, 48, 223-244. doi:10.2190/EC.48.2.f 
Puentedura, R. R. (2008). TPCK and SAMR. Retrieved from http://deimos3.apple.com/WebObjects/Core.woa/FeedEnclosure/educationmaine.gov-dz.4185841413.04185841415.4185841494/enclosure.pdf

Puentedura, R. R. (2006). Transformation, technology and education. Retrieved from http://hippasus.com/resources/tte/

Rosenberg, J. M., \& Koehler, M. J. (2015). Context and technological pedagogical content knowledge (TPACK): A systematic review. Journal of Research on Technology in Education, 47(3), 186-210. doi: 10.1080/15391523.2015.1052663

Vagle, M. D. (2014). Crafting phenomenological research. New York: Taylor \& Francis.

Voogt, J., Fisser, P., Pareja Roblin, N. P., Tondeur, J., \& van Braak, J. (2013). Technological pedagogical content knowledge - A review of the literature. Journal of Computer Assisted Learning, 29, 109-121. doi:10.1111/j.1365-2729.2012.00487.x 


\section{Author Bios:}

Judi Harris is the Pavey Family Chair in Educational Technology at the College of William \& Mary. Her work focuses on teachers' TPACK, planning, and professional learning about technology integration.

Mark Hofer is a Professor in Educational Technology at the College of William \& Mary. His work focuses on TPACK-based technology integration and educational innovation.

\section{Acknowledgement:}

The authors wish to express their deep appreciation to Mr. Joseph J. Plumeri, whose 2012 Award for Faculty Excellence made the symposium and corresponding research described in this article possible. 